\title{
Germline mutations in a clinic-based series of pregnancy associated breast cancer patients
}

\author{
Eleni Zografos ${ }^{1}$, Anna-Maria Korakiti', Angeliki Andrikopoulou', loannis Rellias², Constantine Dimitrakakis², \\ Spyridon Marinopoulos², Aris Giannos², Antonios Keramopoulos ${ }^{3}$, Nikolaos Bredakis ${ }^{3}$, \\ Meletios-Athanasios Dimopoulos ${ }^{1}$ and Flora Zagouri ${ }^{{ }^{*}}$
}

\begin{abstract}
Background: Pregnancy-associated breast cancer (PABC) defined as breast cancer diagnosed during gestation, lactation or within 1 year after delivery, represents a truly challenging situation with significantly increasing incidence rate. The genomic background of $\mathrm{PABC}$ has only recently been addressed while the underlying mechanisms of the disease still remain unknown. This analysis aims to further elucidate the frequency of PABC cases attributable to genetic predisposition and identify specific cancer susceptibility genes characterizing PABC.

Methods: A comprehensive 94-cancer gene panel was implemented in a cohort of 20 PABC patients treated in our clinic and descriptive correlation was performed among the results and the patients' clinicopathological data.

Results: In the present study, 35\% of PABC patients tested carried pathogenic mutations in two known cancer predisposition genes (BRCA1 and CHEK2). In total, 30\% of the patients carried BRCA1 pathogenic variants. An additional $5 \%$ carried pathogenic variants in the CHEK2 gene. Variants of unknown/uncertain significance (VUS) in breast cancer susceptibility genes BRCA2, CHEK2 and BRIP1 were also identified in three different PABC patients (15\%). Not all patients carrying germline mutations reported known family history of cancer.

Conclusions: Genetic testing should be considered as an option for PABC patients since the disease is highly associated with genetic susceptibility among other predisposing factors. Germline mutation identification may further modify PABC management approach and improve the prognostic outcome.
\end{abstract}

Keywords: Breast cancer, Pregnancy, Germline mutation, BRCA1, BRCA2, CHEK2, BRIP1

\section{Introduction}

Breast cancer $(\mathrm{BC})$ is the most frequent malignancy diagnosed in women; this observation generally applies to both the pregnant and the non-pregnant population $[1$, 2]. Pregnancy-associated breast cancer (PABC) is a complex situation that is commonly defined as breast cancer

\footnotetext{
* Correspondence: florazagouri@yahoo.co.uk

'Department of Clinical Therapeutics, Alexandra Hospital, School of Medicine, National and Kapodistrian University of Athens, 80 Vasilissis Sofias Avenue, 11528 Athens, Greece

Full list of author information is available at the end of the article
}

diagnosed during the period of pregnancy, lactation or within 12 months following delivery [3]. Up until today, $\mathrm{PABC}$ has been regarded as a rare entity since it accounts for only $0.2-3.8 \%$ of all breast cancer cases [4]. However, it has been well established that $\mathrm{BC}$ incidence increases with age, until the seventh decade [5]. Consequently, due to the social phenomenon of delayed childbearing, the incidence of PABC is currently on the rise in developing countries [6]. As far as developed countries are concerned, the application of non-invasive prenatal testing (NIPT) in all pregnant women today aiming

(c) The Author(s). 2021 Open Access This article is licensed under a Creative Commons Attribution 4.0 International License, which permits use, sharing, adaptation, distribution and reproduction in any medium or format, as long as you give appropriate credit to the original author(s) and the source, provide a link to the Creative Commons licence, and indicate if changes were made. The images or other third party material in this article are included in the article's Creative Commons licence, unless indicated otherwise in a credit line to the material. If material is not included in the article's Creative Commons licence and your intended use is not permitted by statutory regulation or exceeds the permitted use, you will need to obtain permission directly from the copyright holder. To view a copy of this licence, visit http://creativecommons.org/licenses/by/4.0/. The Creative Commons Public Domain Dedication waiver (http://creativecommons.org/publicdomain/zero/1.0/) applies to the data made available in this article, unless otherwise stated in a credit line to the data. 
to identify chromosomal abnormalities in the fetus, has significantly increased the detection of asymptomatic $\mathrm{PABC}$ patients $[7,8]$. Additionally, the proportion of premenopausal women diagnosed with $\mathrm{BC}$ has increased substantially, with one in forty women diagnosed being under the age of 35 [9]. Taking all the above into account, $\mathrm{PABC}$ is expected to gain more scientific interest in the following years, in order to ensure that this rare and heterogenic population is offered the best individualized management for both maternal and fetal well-being.

Regarding the heredity of the disease, hallmark studies on familial BC have resulted in the identification of clinically relevant cancer susceptibility genes $[10,11]$. Notably, most pregnancies occur under the age of 40 , which is the age group in which BC has been more commonly associated with a positive family history and a higher occurrence of germline mutations [12]. In a study utilizing multiple-gene panel testing, $23 \%$ of breast malignancies in young women were related to germline mutations in known cancer predisposition genes such as $B R C A 1 / 2, C H E K 2, A T M$ and PALB2 [13]. In this setting, the latest international guidelines strongly recommend that genetic testing for high and moderate risk cancer susceptibility genes should be offered to every woman under the age of 50 with $\mathrm{BC}$, thus encompassing $\mathrm{PABC}$ patients $[14,15]$. Additionally, tumors in PABC patients bear distinct biological characteristics that deem them more aggressive, including higher grade and proliferation rates, advanced $\mathrm{T}$ stage at diagnosis, nodal involvement, greater prevalence of the triple-negative subtype (TNBC), and hormone receptor negativity [16]. Consequently, the genetic risk evaluation in this cohort of patients can have a substantial impact on PABC management and follow-up, offering a significant benefit not only to the affected mother to be, but also to family members [17].

Still, the genetic background of $\mathrm{PABC}$ remains an understudied field, despite the fact than in recent years the incorporation of multi-gene panel testing into clinical practice has enabled researchers to more accurately and cost-effectively estimate the proportion of cancers attributable to genetic predisposition and hereditary cancer syndromes [18]. Notably, numerous genes with nonsilent mutations have been found to be differentially expressed between PABC and non-PABCpatient-derived tissues, as it was demonstrated in a recent systematic review published by members of our research group [19], implying a differential genomic background between pregnancy and non-pregnancy associated $\mathrm{BC}$. In the current study, we applied multiple-gene panel testing to 94 cancer susceptibility genes aiming to identify the proportion of $\mathrm{PABC}$ cases attributable to genetic predisposition and to assess the prevalence of germline (i.e. inherited) mutations in PABC patients treated in our clinic.

\section{Materials and methods}

In this cohort study, 20 women diagnosed with breast cancer during pregnancy or in the first year after delivery were enrolled. All participants were required to have completed the 18th year of age and to have attended the Breast Unit of the Obstetrical/Gynecological Clinic or the Department of Clinical Therapeutics of the National and Kapodistrian University of Athens, at the Alexandra Hospital in Athens, Greece. The sample was pooled from the hospital's patient database according to the abovementioned inclusion criteria. The study was approved by the Institutional Review Board (IRB) of the participating hospital.

Participation was voluntary and once informed consent was granted by each participant, medical files of the patients were reviewed and researchers interviewed enrollees in person to collect demographic and clinical data, including age at diagnosis, family cancer history, prior genetic testing results, histopathologic evaluation (tumor stage, size, grade, lymph node status, hormone receptor, and HER2 status). Breast cancer diagnosis was established based on a combination of standard clinical, radiological and histological criteria [20]. Finally, a blood sample was collected from each PABC patient.

Subsequently, genomic DNA was isolated from whole blood using the QIAsymphony DSP DNA Mini Kit (Qiagen, Germantown, USA) and used to prepare indexed libraries to target the sequence of 94 cancer predisposing genes using the Trusight Cancer Panel - Nextera DNA Flex Pre-Enrichment Library Prep (Illumina, San Diego, USA). Libraries were qualitatively and quantitatively evaluated using a Fragment Analyzer (Advanced Analytical Technologies, Heidelberg, Germany) and sequenced on a MiSeq genetic analyzer (Illumina, Inc., San Diego, $\mathrm{CA})$, according to the manufacturer's protocols. Annotation was performed against the human reference genome GRCh38 using VariantStudio V.3 (Illumina, Inc., San Diego, CA). Based on the data generated from this software, alterations were identified as pathogenic when classified as disease causing or as variants of unknown significance (VUS) when evidence regarding their pathogenicity was either conflicting or limited [21]. The minimum base and amplicon coverage were $50 x$, and $100 \times$, respectively, while the mean read depth was $182 \times$. All sequenced variants were interpreted according to the recommendations of the American College of Medical Genetics and Genomics and the Association for Molecular Pathology [22]. 


\section{Results}

We have screened 20 PABC patients, unselected for age or family history, for the presence of germline mutations. The detection rate of pathogenic mutations among the cases tested was $35 \%(7 / 20)$. Of those, six patients of our cohort had a pathogenic BRCA1 mutation and one patient a CHEK2 mutation. Of note, three PABC patients carried variants of unknown/uncertain significance (VUS) in three breast cancer susceptibility genes.

\section{Demographic characteristics}

Detailed data concerning the major demographic variables and the pregnancy characteristics of the PABC subjects enrolled in this study are presented in Table 1 , including age, ethnicity, BMI, time of diagnosis, and number of pregnancy. The age of diagnosis ranged from 26 to 45 years, with a mean age of 34 years. The majority of participants was Greek $(18 / 20=90 \%)$, while one was of Albanian (5\%) and one of Romani (5\%) ancestry. According to the body mass index (BMI) chart, $35 \%$ of participants was classified as overweight and $25 \%$ as obese.

Table 1 Demographic Variables of the 20 PABC Patients Enrolled in the Study

\begin{tabular}{|c|c|c|}
\hline & Frequency & Percent \\
\hline \multicolumn{3}{|l|}{ Age } \\
\hline $25-29$ & 2 & $10 \%$ \\
\hline $30-34$ & 6 & $30 \%$ \\
\hline $35-39$ & 9 & $45 \%$ \\
\hline 40 and older & 3 & $15 \%$ \\
\hline \multicolumn{3}{|l|}{ Ethnicity } \\
\hline Greek & 18 & $90 \%$ \\
\hline Non-Greek & 2 & $10 \%$ \\
\hline \multicolumn{3}{|l|}{ BMI } \\
\hline$\leq 24.9$ (Normal Weight) & 8 & $40 \%$ \\
\hline 25.0-29.9 (Overweight) & 7 & $35 \%$ \\
\hline$\geq 30.0$ (Obese) & 5 & $25 \%$ \\
\hline \multicolumn{3}{|l|}{ Time of Diagnosis } \\
\hline 1st trimester (weeks 1-12) & 1 & $5 \%$ \\
\hline 2nd trimester (weeks 13-26) & 0 & $0 \%$ \\
\hline 3rd trimester (weeks 27-end) & 8 & $40 \%$ \\
\hline Post-partum (up until 12 months) & 6 & $30 \%$ \\
\hline N/A & 5 & $25 \%$ \\
\hline \multicolumn{3}{|l|}{ Number of pregnancy } \\
\hline $1 \mathrm{st}$ & 4 & $20 \%$ \\
\hline 2nd & 6 & $30 \%$ \\
\hline $3 r d$ & 1 & $5 \%$ \\
\hline 4th & 1 & $5 \%$ \\
\hline N/A & 8 & $40 \%$ \\
\hline
\end{tabular}

\section{Histopathological types}

Histopathological features of pregnancy-associated breast tumors are presented in Table 2. The most frequent histological type among $\mathrm{PABC}$ patients enrolled in our study was invasive ductal carcinoma (IDC) (90\%). Interestingly, among them there were two cases of IDCs with medullary features, which fall into the basal-like molecular subtype [23]: one case concerned a 30-yearold woman diagnosed with $\mathrm{PABC}$ at the 28th week of pregnancy and the other was a case of bilateral disease with asynchronous onset at ages 41 (11 weeks pregnant) and 43 (non-pregnant). Concerning the latter case, the histopathological findings differed between the two diagnoses, since the pregnancy associated tumor exhibited medullary-like features, while two years later the same patient was diagnosed with metaplastic breast cancer of the other breast. Of the remaining $\mathrm{PABC}$ patients, there was one case of invasive lobular carcinoma (ILC) and one case of metaplastic carcinoma of the breast

Table 2 Histopathological Status of PABC Tumors

\begin{tabular}{|c|c|c|}
\hline & Parameters & Numbers (\%) \\
\hline \multirow[t]{3}{*}{ Histological type } & IDC & $18(90 \%)$ \\
\hline & ILC & $1(5 \%)$ \\
\hline & Metaplastic & $1(5 \%)$ \\
\hline \multirow[t]{3}{*}{ Tumor grade } & Low (grade I) & $0(0 \%)$ \\
\hline & Intermediate (grade II) & $4(20 \%)$ \\
\hline & High (grade III) & $16(80 \%)$ \\
\hline \multirow[t]{3}{*}{ Tumor size $(T)$} & $\mathrm{T} 1(\leq 2 \mathrm{~cm})$ & $5(25 \%)$ \\
\hline & $\mathrm{T} 2(>2 \mathrm{~cm}$ but $\leq 5 \mathrm{~cm})$ & $9(45 \%)$ \\
\hline & $\mathrm{T} 3(>5 \mathrm{~cm})$ & $6(30 \%)$ \\
\hline \multirow[t]{2}{*}{ ER } & Negative & $9(45 \%)$ \\
\hline & Positive & $11(55 \%)$ \\
\hline \multirow[t]{2}{*}{$P R$} & Negative & $10(50 \%)$ \\
\hline & Positive & $10(50 \%)$ \\
\hline \multirow[t]{2}{*}{ HER2 } & Negative & $12(60 \%)$ \\
\hline & Positive & $8(40 \%)$ \\
\hline \multirow[t]{3}{*}{ Ki-67 } & Low $(<15 \%)$ & $6(30 \%)$ \\
\hline & Moderate (16-30\%) & $3(15 \%)$ \\
\hline & High (> 30\%) & $11(55 \%)$ \\
\hline \multirow[t]{4}{*}{ Axillary Lymph Nodes } & N0 (0 positive nodes) & $12(60 \%)$ \\
\hline & N1 (1-3 positive nodes) & $2(10 \%)$ \\
\hline & N2 (4-9 positive nodes) & $2(10 \%)$ \\
\hline & N3 ( $\geq 10$ positive nodes) & $4(20 \%)$ \\
\hline \multirow[t]{5}{*}{ Molecular subtypes } & Luminal A & $3(15 \%)$ \\
\hline & Luminal B (HER2 negative) & $4(20 \%)$ \\
\hline & Luminal B (HER2 positive) & $5(25 \%)$ \\
\hline & HER2-enriched & $3(15 \%)$ \\
\hline & Triple negative & $5(25 \%)$ \\
\hline
\end{tabular}


diagnosed simultaneously with ductal carcinoma. The majority of tumors was of high grade (80\%), and pathological measurements regarding tumor size revealed that $75 \%$ of them were above $2 \mathrm{~cm}$ (T2, T3). As far as receptor status is concerned, $45 \%$ of PABC cases were ER negative, $60 \%$ HER 2 negative and $50 \%$ of them PR negative; of note, $30 \%$ of the participants' tumors were classified as triple receptor-negative breast cancer (TNBC). Axillary node infiltration was identified in $40 \%$ of cases.

\section{Germline mutation analysis}

For those with a positive mutation result from genetic testing, Table 3 shows the identified germline mutations in cancer predisposition genes and the exact location of each mutation in the affected gene, in comparison with the family history of hereditary breast and ovarian cancer syndromes as well as other common cancers. Specifically, participant \#553 has a germline mutation (BRCA1: c.5328delC) along with a family history of vulvar cancer, \#750 has a known pathogenic mutation (BRCA1: c. $5212 G>A$ ) with a family history of breast and ovarian cancer, \#2754 is a carrier of a pathogenic mutation (BRCA1: c.5251C > T) with a family history of breast cancer, prostate cancer and basal cell carcinoma (BCC) of the skin, and finally PABC patient \#2740 carries a germline mutation (BRCA1 g.169527_180579del11052) and has a history of endometrial and lung cancer. Interestingly, PABC subjects \#964 and \#749 were identified to have the same pathogenic mutation (BRCA1: $c .3700_{-}$ 3704delGTAAA), however the former has no reported family history, while the latter has a family history of breast and endometrial cancer. Furthermore, one of our patients carried a known pathogenic CHEK2 c.1100delC mutation, despite having no family history of cancer.

Concerning the other CHEK2 variant $(c .1175 C>T)$ that was identified in a 36-year-old patient with Luminal B- HER-2 negative PABC, it is classified as a variant of unknown/uncertain significance (VUS). Furthermore, another 37yo patient (\#3227) carried a VUS in BRCA2 (c.8386C $>$ T), while having Luminal A-HER-2 negative $\mathrm{BC}$ and no cancer family history. Lastly, patient \#2122 is a carrier of a VUS in the BRIP1 gene; this PABC patient was diagnosed five months post-partum with Luminal BHER-2 negative breast cancer at 32 years of age and had a positive family history of cancer, including a first- and a second- degree relative with prostate and breast cancer respectively.

\section{Discussion}

In this descriptive study we have established the prevalence of BRCA1 germline mutations in a group of 20 pregnancy associated breast cancer patients, which were selected regardless of family history. All in all, we identified seven PABC patients carrying known pathogenic germline mutations (35\%), six of them in the BRCA1 gene and one in the CHEK2 gene. Additionally, variants of unknown/uncertain significance (VUS) in breast cancer susceptibility genes CHEK2, BRCA2 and BRIP1 were determined to be present in three different PABC patients $(15 \%)$. To our knowledge, this is the first recent study aiming to investigate the germline mutation frequency and spectra in a clinic-based series of PABC patients.

Table 3 Germline mutations identified in PABC cases

\begin{tabular}{|c|c|c|c|c|c|}
\hline ID & Mutation (cDNA) & Mutation (protein) & $\begin{array}{l}\text { Chromosome- } \\
\text { Exon }\end{array}$ & $\begin{array}{l}\text { Clinical } \\
\text { Significance }\end{array}$ & Family History \\
\hline \#553 & BRCA1 c.5328delC & p.Thr1777fs & chr17 exon 21 & Pathogenic & 2nd degree relative: Vulvar cancer \\
\hline \#964 & BRCA1 c.3700_3704delGTAAA & p.Val1234GInfs & chr17-exon 11 & Pathogenic & No \\
\hline \#749 & BRCA1 c.3700_3704delGTAAA & p.Val1234GInfs & chr17-exon 11 & Pathogenic & $\begin{array}{l}\text { 2nd degree relatives: Breast, Endometrial } \\
\text { cancer }\end{array}$ \\
\hline \#750 & BRCA1 c.5212G >A & p.Gly1738Arg & chr17- exon 20 & Pathogenic & 2nd degree relatives: Breast, Ovarian cancer \\
\hline \#2754 & BRCA1 C.5251C > T & p.Arg1751X & chr17-exon 20 & Pathogenic & $\begin{array}{l}\text { 2nd degree relatives: Breast, Prostate cancer, } \\
B C C\end{array}$ \\
\hline$\# 2740$ & $\begin{array}{l}\text { BRCA1 g.169527 } \\
\text { 180579del11052 }\end{array}$ & $\begin{array}{l}\text { p.Gly1803 } \\
\text { Tyr1863del11052 }\end{array}$ & chr17-exons 23,24 & Pathogenic & $\begin{array}{l}\text { 2nd degree relatives: Endometrial, Lung } \\
\text { cancer }\end{array}$ \\
\hline \#1927 & CHEK2 c.1100delC & p.Thr367Metfs X1 & chr22-exon10 & Pathogenic & No \\
\hline \#3227 & $B R C A 2$ c.8386C $>T$ & p.Pro2796Ser & chr13 exon 18 & VUS & No \\
\hline \#1045 & CHEK2 C. $1175 C>T$ & p.Ala392Val & chr22- exon 20 & VUS & No \\
\hline \#2122 & BRIP1 c.2285G > A & p.Arg762His & chr17-exon 1 & VUS & $\begin{array}{l}\text { 1st degree relative: Prostate cancer } \\
\text { 2nd degree relative: Breast cancer }\end{array}$ \\
\hline
\end{tabular}

Note: Participants are identified by patient registry number along with their mutation and family history of cancer including hereditary breast and ovarian cancer syndrome (HBOC) - cancers, Basal cell carcinoma (BCC) of the skin, Variants of Unknown Significance (VUS), c. = coding DNA sequence, g. = genomic sequence, p. $=$ protein sequence 
The notably high frequency of $B R C A 1$ mutations found in the present PABC group (30\%) places pregnant breast cancer patients in a high-risk setting. Previous studies, however heterogenous they are, report high $B R C A 1$ mutation prevalence in $\mathrm{PABC}$ patients, ranging from $11.4-19.6 \%$ [24, 25]. In this setting, PABC patients with germline mutations in $\mathrm{BC}$ susceptibility genes should be placed under close clinical monitoring, in accordance to the evidence-based clinical practice guidelines that have been developed to ensure the appropriate management for carriers of a $B R C A$ pathogenic variant $[15,26]$. This suggestion is consistent with the findings of the only similar study to ours published more than two decades ago by Johansson et al. (1998), who investigated the influence of pregnancy on the risk of developing breast cancer in germline BRCA1/2 mutation carriers [27]. According to their results, more women with BRCA1 mutations developed PABC and in the same context they proposed close monitoring of women with $B R C A 1$ familial mutations during and after pregnancy, thus substantiating our observations.

Nowadays, reports state that $B R C A 1 / 2$ mutations account for only approximately $50 \%$ of the identifiable germline cancer predisposition variants in $\mathrm{BC}$ patients [28]. In parallel, overwhelming evidence suggest that germline pathogenic variants in genes of intermediate penetrance, such as ATM and CHEK2, confer an increased risk of $\mathrm{BC}$, and their analysis is encompassed in gene panels alongside the $B R C A 1 / 2$ genes $[15,29]$. Notably, the checkpoint kinase 2 (CHEK2) gene is a tumor suppressor gene involved in cell cycle checkpoint regulation, DNA damage repair activation and apoptosis [30]. Given its essential role, CHEK2 inherited pathogenic variants have been implicated in $\mathrm{BC}$ predisposition [31]. Of these, the founder mutation CHEK2 c.1100delC is one of the most frequently identified among Northern Europeans [32], while it is considered to be less common in the Mediterranean region, including $\mathrm{BC}$ patients of Greek decent (0.16\%) [33]. This observation does not coincide with our results, since we identified one carrier of the pathogenic CHEK2 c.1100delC and another carrier of a CHEK2 VUS among our PABC patients, highlighting the importance of further investigations of other mutations in order to unravel their contribution to PABC susceptibility.

Notably, multigene panel testing (MGPT) allows the sequencing of multiple genes simultaneously and has offered a cost effective and efficient way to assess cancer genetics in a phenotypically directed clinical setting [28, 34]. Multigene panel tests in general depict more clearly the proportion of breast cancers attributable to genetic predisposition, since they allow detection of even moderate or low penetrance genetic variants [35]. However, there are several issues to take into consideration regarding their use. Specifically, as gene panel testing options for breast cancer risk assessment continue to grow in variety, the specific multigene test that will be used should be chosen carefully. From a clinical perspective, choosing a gene panel that analyses a wide array of moderate or low penetrance genes may lead to the identification of genetic variants which are not medically actionable and thus do not exhibit the attendant cancer prevention benefits [36]. Additionally, multigene tests increase the likelihood of detecting a variant of unknown/ uncertain significance (VUS). These VUSs add complexity that may cause difficulty for clinicians in making management recommendations and advising patients. In our study, a PABC patient carried a VUS in BRIP1 (BRCA1 interacting protein $\mathrm{C}$-terminal helicase 1 ) which is a gene that contributes to the DNA repair function of BRCA1; the impact of this variant on molecular function and subsequent roles in cancer risk is uncertain. This is not a rare finding, since according to data available in ClinVar, 933 variants in BRIP1 clinically classified as a VUS have been reported to date [37]. However, it is a noteworthy observation, since classification of VUSs identified in PABC patients can contribute to earlier detection and screening of breast cancer and, as data from multigene panel testing accumulates, eventually improve treatment options in PABC.

Limitations of the study include that large genomic rearrangements (LGRs), such as copy number variants (CNVs) are usually missed by multigene panel testing; hence they were not reported in our study. Furthermore, it is important to point out that our analysis focused on a small number of patients due to the rarity of the disease, deeming our results merely indicative and in need of further confirmation in a larger cohort of patients, in order to draw safe conclusions on whether a pathogenic variant of a gene can be associated with PABC. Lastly, since this is a descriptive study aiming to assess the prevalence of germline mutations in PABC, the limitations naturally include the absence of a comparison group. The approach utilized does not allow for causal statements; however, our results imply a noteworthy correlation and support the recommendation of at least $B R C A 1$ testing for all PABC patients, regardless of family history and age of diagnosis.

\section{Conclusions}

In conclusion, this study highlights the high frequency of PABC cases attributable to genetic predisposition, indicating that genetic testing at an appropriate time is of great importance for this sub-group, since it might ensure that $\mathrm{PABC}$ patients receive the most appropriate treatment in respect to their specific needs and their sensitive situation. Additionally, our results imply a potential use of multigene panel testing that is not limited 
to young women at high risk but extends to patients with no family history. Interestingly, some of the PABC patients included in this study had family history of breast, ovarian, prostate, colorectal or endometrial cancer, while others reported no family history of malignancies, even though they had a positive result of genetic testing for pathogenic variants in high-risk genes. Taken together, these observations indicate that family history of cancer remains an important variable during decision-making about genetic testing among PABC patients, but it should not be the only criteria for patient selection if we want to assure that carriers will not be missed. Lastly, the use of multi-gene panel testing for hereditary breast cancer risk, not limited to BRCA1/2 pathogenic mutations, is essential to increase the likelihood of detecting an underlying germline genetic component and achieve better PABC patient outcomes. Unfortunately, as already mentioned the incidence of pregnancy-associated breast cancer is expected to increase considerably in the years to come while the introduction of non-invasive prenatal testing has led to higher cancer detection rates in pregnant women [38]; therefore, further research in a larger cohort of patients is deemed necessary.

\section{Acknowledgements}

Not applicable.

\section{Authors' contributions}

FZ conceptualized the project and the methodology. EZ and AMK, with the support of AA, analyzed the data, generated Tables 1,2 and 3, and prepared the original draft under the supervision of $F Z$ and MAD. IR, $C D, S M, A G, A K$, and NB have been involved in the collection of samples and performed data curation. MAD was actively involved in the interpretation of the results, providing important intellectual content. All authors provided critical feedback, contributed to the manuscript, and approved the final version in accordance with criteria established by the International Committee of Medical Journal Editors (ICMJE).

\section{Funding}

There was no specific funding available for this research study.

\section{Availability of data and materials}

All data generated or analyzed during this study are included in this published article.

\section{Declarations}

\section{Ethics approval and consent to participate}

The present study was performed in accordance to the ethical standards of the institution and followed the tenets of the Helsinki Declaration; ethics approval was granted by the Institutional Review Board of the Alexandra Hospital in Athens, Greece, and written informed consent was obtained from all participants.

\section{Consent for publication}

Not applicable.

\section{Competing interests}

The authors declare the following financial interests/personal relationships which may be considered as potential competing interests: $F Z$ has received honoraria for lectures and has served in an advisory role for Astra-Zeneca, Daiichi, Eli-Lilly, Merck, Novartis, Pfizer, and Roche. MAD has received honoraria from participation in advisory boards from Amgen, Bristol-Myers-Squibb,
Celgene, Janssen, Takeda. The remaining authors (EZ, AMK, AA, IR, CD, SM, $A G, A K$, and NB) declare that the research was conducted in the absence of any commercial or financial relationships that could be construed as potential conflict of interest.

\section{Author details}

'Department of Clinical Therapeutics, Alexandra Hospital, School of Medicine, National and Kapodistrian University of Athens, 80 Vasilissis Sofias Avenue, 11528 Athens, Greece. ${ }^{2}$ Department of Obstetrics and Gynecology, Alexandra Hospital, School of Medicine, National and Kapodistrian University of Athens, Athens, Greece. ${ }^{3}$ Breast Center, laso Women's Health Hospital, Athens, Greece.

Received: 27 February 2021 Accepted: 30 April 2021

Published online: 19 May 2021

\section{References}

1. Parazzini F, Franchi M, Tavani A, Negri E, Peccatori FA. Frequency of pregnancy related Cancer: a population based linkage study in Lombardy, Italy. Int J Gynecol Cancer. 2017;27(3):613-9. https://doi.org/10.1097//GC. 0000000000000904.

2. de Haan J, Verheecke M, Van Calsteren K, Van Calster B, Shmakov RG, Mhallem Gziri M, et al. Oncological management and obstetric and neonatal outcomes for women diagnosed with cancer during pregnancy: a 20-year international cohort study of 1170 patients. Lancet Oncol. 2018; 19(3):337-46. https://doi.org/10.1016/S1470-2045(18)30059-7.

3. Wang B, Yang Y, Jiang Z, Zhao J, Mao Y, Liu J, et al. Clinicopathological characteristics, diagnosis, and prognosis of pregnancy-associated breast cancer. Thorac Cancer. 2019;10(5):1060-8. https://doi.org/10.1111/17597714.13045.

4. Vinatier E, Merlot B, Poncelet E, Collinet P, Vinatier D. Breast cancer during pregnancy. Eur J Obstet Gynecol Reprod Biol. 2009;147(1):9-14. https://doi. org/10.1016/j.ejogrb.2009.06.030.

5. Ferlay J, Soerjomataram I, Dikshit R, Eser S, Mathers C, Rebelo M, et al. Cancer incidence and mortality worldwide: sources, methods and major patterns in GLOBOCAN 2012. Int J Cancer. 2015;136(5):E359-86. https://doi. org/10.1002/ijc.29210.

6. Lee GE, Mayer EL, Partridge A. Prognosis of pregnancy-associated breast cancer. Breast Cancer Res Treat. 2017;163(3):417-21. https://doi.org/10.1007/ s10549-017-4224-6.

7. Amant F, Verheecke M, Wlodarska I, Dehaspe L, Brady P, Brison N, et al. Presymptomatic identification of cancers in pregnant women during noninvasive prenatal testing. JAMA Oncol. 2015;1(6):814-9. https://doi.org/1 0.1001/jamaoncol.2015.1883.

8. Lenaerts $L$, Jatsenko T, Amant F, Vermeesch JR. Noninvasive prenatal testing and detection of occult maternal malignancies. Clin Chem. 2019;65(12): 1484-6. https://doi.org/10.1373/dlinchem.2019.306548.

9. Cardoso F, Loibl S, Pagani O, Graziottin A, Panizza P, Martincich L, et al. The European Society of Breast Cancer Specialists recommendations for the management of young women with breast cancer. Eur J Cancer. 2012; 48(18):3355-77. https://doi.org/10.1016/j.ejca.2012.10.004.

10. Margaritte P, Bonaiti-Pellie C, King MC, Clerget-Darpoux F. Linkage of familial breast cancer to chromosome 17q21 may not be restricted to earlyonset disease. Am J Hum Genet. 1992;50(6):1231-4. Erratum in: Am J Hum Genet 1993;52(3):654.

11. Rahman N. Realizing the promise of cancer predisposition genes. Nature. 2014;505(7483):302-8. https://doi.org/10.1038/nature12981.

12. Lee $H B$, Han W. Unique features of young age breast cancer and its management. J Breast Cancer. 2014;17(4):301-7. https://doi.org/10.4048/ jbc.2014.17.4.301.

13. Rummel SK, Lovejoy L, Shriver CD, Ellsworth RE. Contribution of germline mutations in cancer predisposition genes to tumor etiology in young women diagnosed with invasive breast cancer. Breast Cancer Res Treat. 2017;164(3):593-601. https://doi.org/10.1007/s10549-017-4291-8.

14. Paluch-Shimon S, Pagani O, Partridge AH, Abulkhair O, Cardoso MJ, Dent RA, et al. ESO-ESMO 3rd international consensus guidelines for breast cancer in young women (BCY3). Breast. 2017;35:203-17. https://doi.org/10.1 016/j.breast.2017.07.017.

15. Daly MB, Pilarski R, Yurgelun MB, Berry MP, Buys SS, Dickson $P$, et al. Genetic/familial high-risk assessment: Breast, ovarian, and pancreatic,version 
1.2020 featured updates to the NCCN guidelines. JNCCN J Natl Compr Cancer Netw. 2020;18:380-91. https://doi.org/10.6004/jnccn.2020.0017.

16. Murphy CG, Mallam D, Stein S, Patil S, Howard J, Sklarin N, et al. Current or recent pregnancy is associated with adverse pathologic features but not impaired survival in early breast cancer. Cancer. 2012;118(13):3254-9. https://doi.org/10.1002/cncr.26654.

17. Partridge AH, Pagani O, Abulkhair O, Aebi S, Amant F, Azim HA, et al. First international consensus guidelines for breast cancer in young women (BCY1). Breast. 2014;23(3):209-20. https://doi.org/10.1016/j.breast.2014.03.011.

18. Kurian AW, Ward KC, Hamilton AS, Deapen DM, Abrahamse P, Bondarenko I, et al. Uptake, results, and outcomes of germline multiple-gene sequencing after diagnosis of breast cancer. JAMA Oncol. 2018;4(8):1066-72. https://doi. org/10.1001/jamaoncol.2018.0644

19. Korakiti A-M, Moutafi M, Zografos E, Dimopoulos M-A, Zagouri F. The genomic profile of pregnancy-associated breast Cancer: a systematic review. Front Oncol. 2020;10:1773. https://doi.org/10.3389/fonc.2020.01773.

20. Cardoso F, Kyriakides S, Ohno S, Penault-Llorca F, Poortmans P, Rubio IT, et al. ERRATUM: Early breast cancer: ESMO clinical practice guidelines for diagnosis, treatment and follow-up. Ann Oncol. 2019;30(10):1674. https:// doi.org/10.1093/annonc/mdz189.

21. Pesaran T, Karam R, Huether R, Li S, Farber-Katz S, Chamberlin A, et al. Beyond DNA: an integrated and functional approach for classifying Germline variants in breast Cancer genes. Int J Breast Cancer. 2016;2016:110. https://doi.org/10.1155/2016/2469523.

22. Richards S, Aziz N, Bale S, Bick D, Das S, Gastier-Foster J, et al. Standards and guidelines for the interpretation of sequence variants: a joint consensus recommendation of the American College of Medical Genetics and Genomics and the Association for Molecular Pathology. Genet Med. 2015; 17(5):405-24. https://doi.org/10.1038/gim.2015.30.

23. Kleer CG. Carcinoma of the breast with medullary-like features: Diagnostic challenges and relationship with brcal and ezh2 functions. Arch Pathol Lab Med. 2009:133(11):1822-5. https://doi.org/10.1043/1543-2165-133.11.1822.

24. Blanquisett $\mathrm{AH}$, Vicent $\mathrm{CH}$, Gregori JG, Zotano ÁG, Porta VG, Simón AR. Breast cancer in pregnancy: an institutional experience. Ecancermedicalscience. 2015;9. https://doi.org/10.3332/ecancer.2015.551.

25. Gooch JC, Chun J, Kaplowitz E, Guth A, Axelrod D, Shapiro R, et al. Pregnancy-associated breast cancer in a contemporary cohort of newly diagnosed women. Breast J. 2020;26(4):668-71. https://doi.org/10.1111/tbj.13 510 .

26. Tung NM, Boughey JC, Pierce $\sqcup$, Robson ME, Bedrosian I, Dietz JR, et al. Management of hereditary breast cancer: American society of clinical oncology, American society for radiation oncology, and society of surgical oncology guideline. J Clin Oncol. 2020;38(18):2080-106. https://doi.org/10.12 00/JCO.20.00299

27. Johannsson O, Loman N, Borg Å, Olsson H. Pregnancy-associated breast cancer in BRCA1 and BRCA2 germline mutation carriers. Lancet. 1998; 352(9137):1359-60. https://doi.org/10.1016/S0140-6736(05)60750-7.

28. Buys SS, Sandbach JF, Gammon A, Patel G, Kidd J, Brown KL, et al. A study of over 35,000 women with breast cancer tested with a 25-gene panel of hereditary cancer genes. Cancer. 2017;123(10):1721-30. https://doi.org/10.1 002/cncr.30498.

29. Shiovitz S, Korde LA. Genetics of breast cancer: a topic in evolution. Ann Oncol. 2015:26(7):1291-9. https://doi.org/10.1093/annonc/mdv022.

30. Cai Z, Chehab NH, Pavletich NP. Structure and activation mechanism of the CHK2 DNA damage checkpoint kinase. Mol Cell. 2009;35(6):818-29. https:// doi.org/10.1016/j.molcel.2009.09.007.

31. Stolarova L, Kleiblova P, Janatova M, Soukupova J, Zemankova P, Macurek L, et al. CHEK2 Germline variants in Cancer predisposition: stalemate rather than checkmate. Cells. 2020;9(12). https://doi.org/10.3390/cells9122675.

32. Muranen TA, Greco D, Blomqvist C, Aittomäki K, Khan S, Hogervorst F, et al. Genetic modifiers of CHEK2*1100delC-associated breast cancer risk. Genet Med. 2017;19(5):599-603. https://doi.org/10.1038/gim.2016.147.

33. Apostolou P, Fostira F, Papamentzelopoulou M, Michelli M, Panopoulos C, Fountzilas G, et al. CHEK2 c.1100delC allele is rarely identified in Greek breast cancer cases. Cancer Genet. 2015;208:129-34. https://doi.org/10.1016/ j.cancergen.2015.02.006.

34. Manchanda R, Patel S, Gordeev VS, Antoniou AC, Smith S, Lee A, et al. Costeffectiveness of population-based BRCA1, BRCA2, RAD51C, RAD51D, BRIP1, PALB2 mutation testing in unselected general population women. J Natl Cancer Inst. 2018;1 10(7):714-25. https://doi.org/10.1093/jnci/djx265.
35. Kurian AW, Hare EE, Mills MA, Kingham KE, McPherson L, Whittemore AS, et al. Clinical evaluation of a multiple-gene sequencing panel for hereditary cancer risk assessment. J Clin Oncol. 2014;32(19):2001-9. https://doi.org/1 $0.1200 / J C O .2013 .53 .6607$.

36. Hall MJ, Forman AD, Pilarski R, Wiesner G, Giri VN. Gene panel testing for inherited cancer risk. JNCCN J Natl Compr Cancer Netw. 2014;12(9):1339-46. https://doi.org/10.6004/jnccn.2014.0128.

37. Landrum MJ, Lee JM, Benson M, Brown G, Chao C, Chitipiralla S, et al. ClinVar: public archive of interpretations of clinically relevant variants. Nucleic Acids Res. 2016;44(D1):D862-8. https://doi.org/10.1093/nar/gkv1222.

38. Korakiti AM, Zografos E, van Gerwen M, Amant F, Dimopoulos MA, Zagouri F. Long-term neurodevelopmental outcome of children after in utero exposure to chemotherapy. Cancers. 2020;12(12):1-16. https://doi.org/10.33 90/cancers12123623.

\section{Publisher's Note}

Springer Nature remains neutral with regard to jurisdictional claims in published maps and institutional affiliations.
Ready to submit your research? Choose BMC and benefit from:

- fast, convenient online submission

- thorough peer review by experienced researchers in your field

- rapid publication on acceptance

- support for research data, including large and complex data types

- gold Open Access which fosters wider collaboration and increased citations

- maximum visibility for your research: over $100 \mathrm{M}$ website views per year

At BMC, research is always in progress.

Learn more biomedcentral.com/submissions 